\title{
Development of a Design-Time Estimation Model for Complex Engineering Processes
}

\author{
Sara SHAFIEE ${ }^{\mathrm{a}, 1}$, Zaza Nadja Lee HERBERT-HANSEN ${ }^{\mathrm{b}}$, Lars HVAM ${ }^{\mathrm{c}}$, Anders \\ HAUG $^{\mathrm{d}}$, Martin BONEV ${ }^{\mathrm{e}}$ and Niels Henrik MORTENSEN ${ }^{\mathrm{a}}$ \\ ${ }^{a}$ Department of Mechanical Engineering, Technical University of Denmark, Denmark \\ ${ }^{\mathrm{b}}$ Fiskeristyrelsen, Copenhagen, Denmark \\ ${ }^{c}$ Department of Management Engineering, Technical University of Denmark, Denmark \\ ${ }^{\mathrm{d}}$ Department of Entrepreneurship and Relationship Management, University of \\ Southern Denmark, Denmark \\ e Porsche Consulting, Hamburg, Germany
}

\begin{abstract}
The current business environment presents challenges for companies, including increased pressure on time to market, customer expectations, cost and increased competition. To overcome the challenges in the new business environment, the companies introduce common products components and variants in order to reduce complexity and improve the performance. Besides, the manufacturers attempt to increase the variety in products and services in response to the personalization demands; which leads to more complexity. However, the companies can improve the due-date setting and resource allocation to optimize internal process performance. This paper describes a design-time estimation model for planning engineering activities based on a quantification of the most important product complexity factors such as: 1) basic components variety, 2) functional requirements, 3) design interdependencies and 4) regulations and standards. Such factors can decrease or increase the expected time consumption for the specification tasks. This paper identifies key factors essential to assessing the expected hours for specific engineering tasks based on a case study and literature review. Qualitative and quantitative information was obtained by means of (i) archival documents, (ii) participant-observations, and (iii) workshops in the case company. These complexity factors are then combined to develop a mathematical design-time estimation model that supports the internal performance optimization in a given engineering design process. Finally, an IT tool is prototyped and tested in an engineering company. In conclusion, the developed model and IT tool assist the case company to improve the estimations for due-date setting and resource allocation to optimize internal process performance.
\end{abstract}

Keywords. Design-time Estimation Model, Complexity Management, Quantifying Complexity, Engineering Design

\section{Introduction}

Engineering tasks include product development, production planning, prototyping and testing and may be organized in parallel and distributed over different locations [1]. The design of engineering process is one of the most important functions in manufacturing companies. Manufacturers attempt to increase the variety in products and services that

\footnotetext{
${ }^{1}$ Corresponding Author, Email: sashaf@dtu.dk.
} 
they provide to their customers [2] to sustain or even gain a competitive advantage in the market and manage to satisfy their customers [3]-[6]. However, it should be mentioned that there is not always a direct relationship between an increase in offering variety through customization and an increased consumer value. The hidden challenge when it comes to managing this increasing variety in an effective and efficient way is difficult realize [7]. The engineering design process can be rather complex, and it affects processes in production, distribution, sales and in general across the entire value chain [8].

To deal with this complexity, a number of methods have been proposed (monetary and non-monetary) [9], [10]. The Main methods proposed include component substitution and product standardization [11], [12]. Other approaches are directed towards process complexity, including more efficient inventory management by reducing the number of variants kept in stock [13], optimization of the production process [14] and process standardization by utilizing a configurator [8], [15]-[17]. In order to reduce process complexity the key methods developed focusing on optimization of the different lifecycle processes [18].

In this study, we investigate how complexity management approaches [18] can support the assessment of engineering changes, to better estimate the time estimations in engineering processes. Furthermore, this paper develops a Design-Time Estimation Model for engineering companies based on complexity quantification. This research will benefit from a combined quantitative and qualitative approach in order to explore the research area and provide rich, deep data [19].

This paper is structured as follows. A literature study is used to define the quantifiable complexity factors. Afterwards, these complexity factors are combined to develop a design-time estimation model that supports the internal performance optimization in the engineering design process. Thereafter, we applied the model to our case company based on the desired scope, characterizing a marine diesel engine. Qualitative and quantitative data at the case company was gathered and the method of data collection was through company visits, presentations and interviews by the senior staff and documentation.

\section{Related work}

This section discusses identification of a more efficient production strategy and process segmentation to distinguish between production and handling of configure to order (CTO), Manufacture To Order (MTO) and Engineer To Order (ETO) products [20]. The different methods for complexity reduction cover elements from both monetary and non-monetary initiatives, indicating a dichotomy of the topic [21]. Two approaches for monetary complexity assessment are the 5-step approach of Hvam et al. [18] and the management theories [22]. The five steps of complexity reduction are briefly described in this section [18].

Step 1: Define the scope of the products and processes to include in the analysis. Wilson \& Perumal [22] define the first step as the recognition of the situation, which includes a general understanding of the significant relationships and their resulting tradeoffs. Hvam et al. [18] specifies further that the first step contains the definition of the scope and boundaries of the analysis, the number of included elements, and the level of the analysis (e.g. product vs. product family). Furthermore, the focus area within the 
supply chain (e.g. development, production sales) and the region (e.g. certain production side, market) need to be defined.

Step 2: ABC Analysis of products. During the second step of the 5-step approach of Hvam et al. [18], a Double Pareto Analysis is carried out for the chosen elements. One Pareto Analysis is based on the net revenue and the other one based on the contribution margin. In this analysis, the individual elements are grouped in three categories, according to their accumulated net revenue and contribution margin: " $\mathrm{A}$ " elements have $80 \%$ of the net revenue and the contribution margin, " $\mathrm{B}$ " elements have $15 \%$ and " $\mathrm{C}$ " elements the remaining 5\% [18], [22], [23].

Step 3: Identification and quantification of the most significant complexity cost factors. Hvam [18] analyses the possible areas where the cost is unevenly distributed between the elements in the third step. The most significant cost areas are identified based on an executed cost distribution for all elements in combination with a brainstorming process [22]. During this analysis, the identified complexity cost factors are quantified in order to develop a quantitative basis for the later optimization [10], [22].

Step 4: Identification and quantification of possible initiatives for the reduction of complexity costs. In step 4, possible initiatives for reducing the complexity costs are created by changing the product range, business processes or organization. They are clustered in short-term examples (low-hanging gains e.g. adjustments of the product assortment), mid-term and long-term implementation (e.g. re-design of products and major changes in the production flow or warehouse) [22].

Step 5: Evaluation and prioritization of initiatives and establishment of the complexity cost reduction program. Step 5 combines the findings of the previous steps by implementing a complexity reduction program, which furthermore enables handling complexity [24]. The proposed initiatives are evaluated and a plan for their short-term, mid-term and long-term implementation is made, including the insights gained through the complexity analysis. The effects of the identified complexity drivers are limited or eliminated in order to decrease the impact of complexity [18].

\section{Design-estimation model development}

This paper identifies the complexity factors for the engineering design process based on the literature and experts at the case company. The framework will include the complexity factors; the main complexity drivers; the current complexity level; the performance consequences caused by complexity; the parts which are most affected by complexity; the complexity factors influencing the engineering design process; the quantification of complexity in the engineering design process based on metrics; the estimation of design-time based on the complexity quantification; the design-time estimation as a complexity management tool to handle complexity efficiently and effectively in the engineering design departments.

\subsection{First criterion: Overall complexity is composed of a static complexity component and a dynamic component}

Griffin [25] predicts the design lead-time based on project complexity which has two components. One component is the basic complexity (product complexity and management complexity), which is static for a given product. The other component is 
the amount of change, which is dynamic for a given product in dependence from a specific project.

Project complexity $=($ product complexity + management complexity $) *$ amount of changes (\%) $\left[D T_{p s}=y_{s t}+m+\%\right.$ change $]$

Where;

Management complexity $=$ no. of technologies/functional specialties across the project that needs to be managed

Amount of change $(\%)=$ changes to product and manufacturing process (not to customer) in \%

For the design-time estimation model, the general structure of Griffin [25] fulfils the first criterion in our case study, since the project complexity can be decomposed in a static and a dynamic component. The necessary time to deliver the Sub-functions (SF) is therefore calculated based on this project complexity (Figure 1).

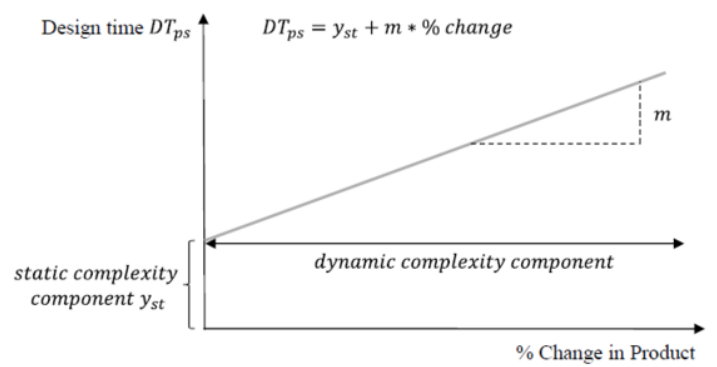

Figure 1. Static and dynamic complexity relationship

\subsection{Second Criterion: Inclusion of particularities of an engineering design process}

Grabenstetter \& Usher [26] determine job complexity in an engineer-to-order (ETO) environment. An ETO product is thereby defined as the culmination of unique designs prepared for specific customer order. The theory is validated to be applicable to the setting of our case company because the design of a ship engine is also a culmination of unique designs based on the customer requirements. Grabenstetter \& Usher [26] calculate the complexity based flow time for job with their complexity equation. As shown in the following, this complexity equation is based on seven complexity factors.

$C F j=\beta_{1} x_{1}+\beta_{2} x_{2}+\beta_{3} x_{3}+\beta_{4} x_{4}+\beta_{5} x_{5}+\beta_{6} x_{6}+\beta_{7} x_{7}$

With;

$$
\begin{aligned}
& C F j=\text { Complexity bases flow time for job } j \\
& \beta_{n}=\text { Slope value for factor } x_{n} \\
& x_{1}=\text { Number of functional requirements } \\
& x_{2}=\text { Number of basic requirements } \\
& x_{3}=\text { Number of design requirements } \\
& x_{4}=\text { Number of technologies }
\end{aligned}
$$




$$
\begin{aligned}
& x_{5}=\text { Number of regulations and standards } \\
& x_{6}=\text { Number of subsystems } \\
& x_{7}=\text { Number of reference job }
\end{aligned}
$$

The first factor $x_{1}$ represents the number of functional requirements, for example the desired behaviour of the system in development. The number of required functionalities influences thereby the amount of time needed for the design. $X_{2}$ is the number of standard components in the product. $x_{3}$ in the approach of Grabenstetter \& Usher [26] represents the number of design dependencies and assesses thereby the presence of coupling between elements in a product. The number of different technologies, $x_{4}$, takes into account that the time consumption is directly connected to the level of technology. The presence of certain standards and regulations also has an influence on the flow time $\left(x_{5}\right)$. The sixth factor $\left(x_{6}\right)$ counts the number of subsystems in a manufacturing environment. However, this factor is defined as a categorical variable based on estimations, since the exact number of subassemblies is not known at an early point in the development. Finally $x_{7}$ reflects the uncertainty reduction in case of a similar job and can be used as a reference model.

\subsection{Third Criterion: Model based on objectively quantifiable complexity factors}

The third criterion is already fulfilled through the use of the theories by Grabenstetter \& Usher [26] and Griffin [25] because both models are based on objectively quantifiable complexity metrics. Despite the confirmation problems of Griffin [27], the first model Griffin [25] showed positive results and fulfils the first criterion for the design-time estimation model. The theory of Grabenstetter \& Usher [26] furthermore fulfils the second criterion because of the similar setting in an engineering company. The theory of Bashir \& Thomson [28], [29] on the other hand is not considered as the applicability in the industry is not proven and also because the model is mainly based on estimations rather than objective complexity metrics. Therefore, a hybrid method based on the theories of Griffin [25] and Grabenstetter \& Usher [26] is used for the design-time estimation model at the case company and for the selected engine type. Combining the complexity factors described above with the selected theories results presented here, the calculation of the design-time is shown below.

Design time per product for customer order $=\varphi * \sum_{i=1}^{n}$ Design Time $S F_{i}$

With;

$$
\begin{aligned}
& \varphi=\text { weighting factor for product } \\
& n=\text { number of active } S F_{S}
\end{aligned}
$$

The design-time for a specific SF is calculated using the following equation.

Under the condition: Depth of change $>0$

$D T_{p s}=\alpha_{s} *$ Depth of change

$$
\begin{gathered}
+(\beta * \text { product complexity }+\gamma * \text { process complexity }+\delta \\
* \text { organizational comlexity })
\end{gathered}
$$

With; $D T_{p s}=$ Design Time depending on project and $S F_{S}$ 


$$
\begin{gathered}
\alpha_{s}=\text { Slope value for depth of change } \\
\beta, \gamma, \delta=\text { weighting factors }
\end{gathered}
$$

$$
\begin{aligned}
& \text { Product complexity }=\text { number of functions }+ \text { maturity level of design } \\
& + \text { level of connectivity }+ \text { level of influence from } \mathrm{DSO}^{2} \\
& + \text { level of quality requirements }
\end{aligned}
$$

$$
\begin{aligned}
& \text { Process complexity } \\
& =\text { number of process steps } \\
& + \text { number of related design activities }
\end{aligned}
$$

$$
\begin{aligned}
& \text { Organizational complexity } \\
& \qquad \begin{array}{l}
=\text { Connectivity of activities }+ \text { multidisciplinary } \\
+ \text { experience of the engineer }
\end{array}
\end{aligned}
$$

Where subscript $\mathrm{s}$ Referes to work specific. The level of influence from DSO assesses similar to the previous factor, the level of influence on a specific SF. However, this time the influence from the DSO input values. As a result of the limitations to access data, the first prototype of the model is composed of four complexity factors. These are described bellow.

\section{Depth of change $-x$}

The type of module (CTO, MTO, ETO) highly influences the required design-time. In case a product can be simply re-used, close to no time is necessary, while for a new designed product a significant amount of time is needed. The depth of change defines, therefore, if the design-time needs to be calculated. In case of $x>0$, $x$ defines the weighting of the other factors. While, For CTOs, $1<\mathrm{x}=<20 \%$, for MTO, $20 \%<\mathrm{x}=<$ $80 \%$ and for ETO, $80 \%<x=<100 \%$. During the feasibility study, the size of $x$ for the MTO designs needs to be defined through interviews with experienced designers.

2. Number of functional requirements $-y_{1}$

In every product, some modules have more functions than others and are therefore typically more complex for the design process. In addition, some of those functions can be decomposed in several sub-functions and are therefore more difficult to be developed. The concept of functional decomposition introduced is an appropriate method to assess this factor using the equation described below, which calculates the complexity depending on the number of functions and the number of hierarchies:

\# of fuctional requirements $y_{1}=\sum_{i=1}^{n N} F_{i} j$

With; $f=$ Total \# of functional requirements

$$
\begin{aligned}
& f_{i}=\text { \# of individual functions in module } i \text { at level } j \\
& j=\text { level of functional tree } \\
& N=\text { Total \# of levels in functional tree }
\end{aligned}
$$

${ }^{2}$ When a licensee wishes to order a new engine at the case company, we used a webbased application called DSO. 
The factor is then rated based on the scale shown in Figure 2. The data to assess this factor is gained with the help of a functional tree for every chosen SF. In a functional tree, the functions are represented by blocks, which are connected by branches. The main functions of a SF are represented by blocks in the highest level of the functional tree, the sub-functions are represented by blocks in the lower levels [30]. The number of functions and levels a functional tree is representative for its complexity of the part [28]. The required knowledge of the functions is assessable through interviews as well as the part descriptions.

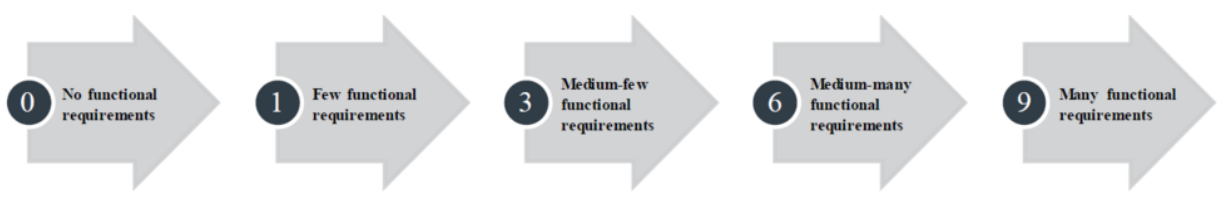

Figure 2. Scale to weight the number of functional requirements.

\section{Level of connectivity $-y_{2}$}

The level of connectivity measures how many SFs have an influence on one specific SF. It is assumed that the higher this connectivity is, the longer the design-time is due to possible iterations during the design process. The data acquisition for the factor is based on a design structure matrix between the SFs. The number of existing links is counted and grouped according to the scale introduced by Orfi et al. [31] in Figure 3.
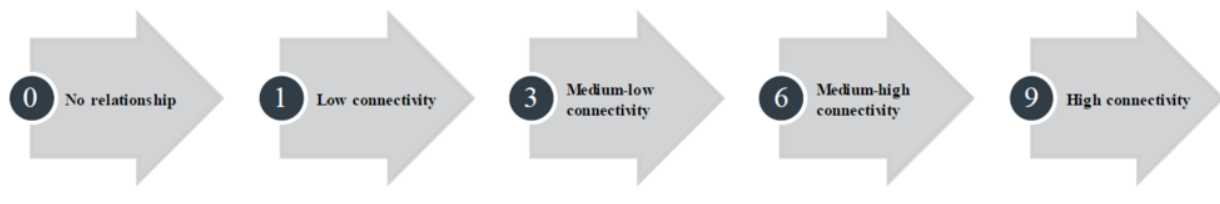

Figure 3. Scale to weight the level of connectivity [31].

4. Level of influence from $\mathrm{DSO}-y_{3}$

This factor assesses similar to the previous factor the level of influence on a specific SF. However, this time not the influence from other SFs is assessed but the influence from the DSO input values. The data acquisition is hereby done with a company's internal design tool and assessed. It is ranked based on the scale introduced in Figure 4.
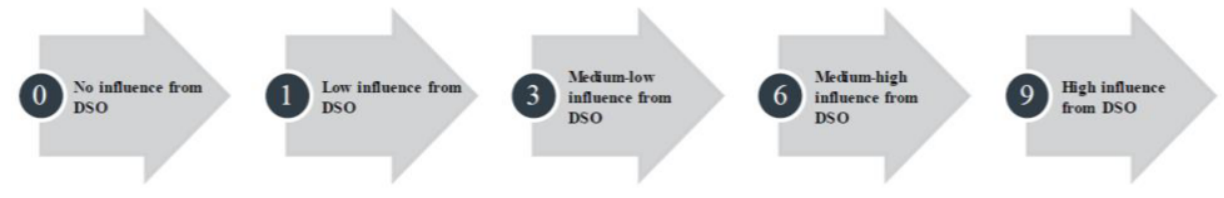

Figure 4. Scale to weight the influence from the DSO.

It is now possible to present the first Design-Time Estimation Model for the case company. The limitations and chosen four complexity factors are combined to the following complexity equation.

$D T_{p s}=\alpha_{s} * x+\left(\beta_{1} \gamma_{1}+\beta_{2} \gamma_{2}+\beta_{3} \gamma_{3}+\Delta \vartheta_{s t}\right)+\Delta \vartheta_{d y}$

With; 


$$
\begin{aligned}
& \alpha_{s}=\text { slope value for depth of change of } S F S \\
& \beta_{1}, \beta_{2}, \beta_{3}=\text { weighting factors } \\
& x=\text { depth of change } \\
& \gamma_{1}, \gamma_{2}, \gamma_{3}=\text { number of functional requirements, level of connectivity, level of } \\
& \text { influence } \\
& \Delta \vartheta_{s t}, \Delta \vartheta_{d y}=\text { Uncertainty factor for missing static and dynamic complexity } \\
& \text { factors }
\end{aligned}
$$

\section{Case study}

The case company was selected based on specific criteria include (i) it is an engineering organization, (ii) it is challenged by time estimation for their engineering services and (iii) it gave us the access to management and data [32]. The case company is one of the three leading suppliers of turbo machines specialized in marine engines. The method ensured accurate representation and enabled triangulation of the findings between different sources of information thereby improving validity.

The model created using the developed method and software is visualised in Figure 5. The relevant complexity factors when designing a marine diesel engine were identified. The eleven identified factors are classified in four groups: engine, product, process and organization and are considered to define the overall complexity of the engine. The design-time estimation model was developed and the overall equation included all complexity factors. These were then limited to fit the scope of this study for the first prototype included four complexity factors. Through this part of the feasibility study, it was proven that the estimation of the design-time is principally possible. Nevertheless, for the model to be value-adding for the company, the data quality needs to be improved. After the necessary data points for all SFs are collected, the output values of the Regression Analysis are used to develop the Excel based design-time estimation tool. For every single SF, the complexity factors and corresponding slope values/weighting factors are implemented and build the data base for the estimation of the design-time. The results of the feasibility study are already implemented to show the principle.

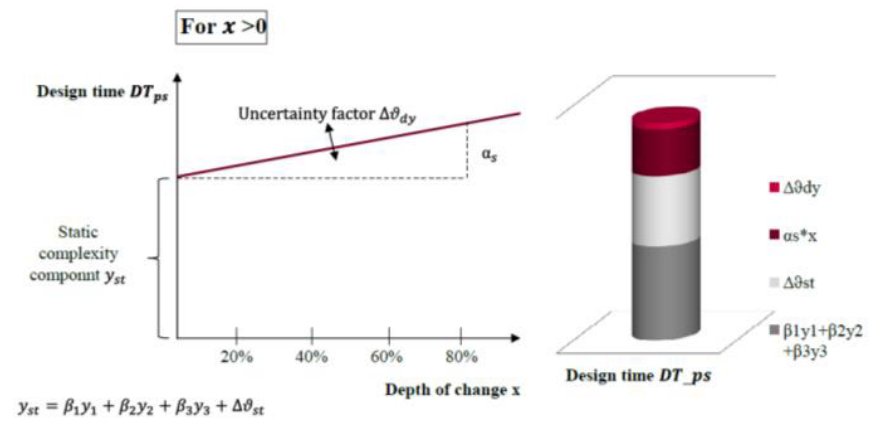

Figure 5. Visualization of the deign-time estimation model for the case company.

\section{Discussions and conclusions}

This paper developed a framework for design time estimation and complexity management. This framework was tested as an IT solution in a case company and further expanded based on these findings. 
We identified the relevant complexity factors when designing a complex engineering product. The identified factors are classified in four groups: engine, product, process and organization and are considered to define the overall complexity of the product. The identified factors consist of two engine, six product, two process and three organizational complexity factors, which are expected to influence the job design-time. The design-time estimation model was developed.

As mentioned, the complexity factors for the case company were limited to fit the scope of this study for the first prototype. Therefore, the engine level is not part of the complexity-adjusted design time and only product complexity is included in the first model due to the high impact and the objective assessment with structural complexity management tools. The case study showed that the source of complexity was variety, which is mainly induced by the demand for customized products and the company strategy. The main complexity drivers were five external and six internal complexity drivers. The external complexity drivers are thereby having a higher influence on the level of complexity. Unfortunately, these external complexity factors cannot be controlled by the company, and we focused mainly on the internal complexity.

The quantification of the complexity in the engineering design process can be done using the previously identified complexity factors and combining them to a mathematical equation that estimates design-time. The developed IT tool for the case company offers an easy and fast option to obtain the estimated design-time for a specific SF as long as only stable complexity factors are included. Nevertheless, two weaknesses of the existing tool should be pointed out: Firstly, the depth of change needs to be assessed manually based on the specifications and the characteristics of the SF and the SF attributes. Secondly, filling in the form for all SFs per engine is effective but not efficient.

In conclusion, the design time estimation model can be used as a complexity management tool to handle complexity efficiently and effectively. The design-time estimation tool has been developed to enable employees and the top management to monitor the performance and workload for a SF based on the level of complexity. This knowledge can furthermore be used to allocate the resources in the most efficient way and to optimize the internal complexity factors in order to handle future challenges. Future research will focus on testing the developed framework in more case companies to further expand and strengthen its industry applicability and validity.

\section{References}

[1] C. Forza and F. Salvador, Product information management for mass customization: connecting customer, front-office and back-office for fast and efficient customization. Palgrave Macmillan, New York, 2007.

[2] H. Wang, Product Variety Induced Complexity and Its Impact on Mixed-Model Assembly Systems and Supply Chains, $\mathrm{PhD}$ thesis, The University of Michigan, 2010.

[3] X. Wan, P. T. Evers, and M. E. Dresner, Too much of a good thing: The impact of product variety on operations and sales performance, Journal of Operations Management, vol. 30, no. 4, pp. 316324, 2012.

[4] B. L. Bayus, W. P. Putsis, B. L. Bayus, and W. P. Putsis, Outcomes Product Proliferation : An Empirical Analysis of Product Line Determinants and Market Outcomes, Marketing Science, vol. 18, no. 2, pp. 137-153, 1999.

[5] N. Xia and S. Rajagopalan, Standard vs. Custom Products: Variety, Lead Time, and Price Competition, Marketing Science, vol. 28, no. 5, pp. 887-900, 2009.

[6] A. Haug, S. Shafiee, and L. Hvam, The costs and benefits of product configuration projects in engineer-to-order companies, Computers in Industry, vol. 105, pp. 133-142, 2019.

[7] B. Berman, Should your firm adopt a mass customization strategy?, Business Horizons, vol. 45, no. 4, pp. 51-60, 2002. 
[8] S. Shafiee, Conceptual Modelling for Product Configuration Systems, PhD thesis, Technical University of Denmark, 2017.

[9] M. Götzfield, Managing Complexity Induced by Product Variety in Manufacturing Companies, $\mathrm{PhD}$ thesis, University of St. Gallen, 2013.

[10] U. Lindemann, M. Maurer and T. Braun, Structural Complexity Management: An Approach for the Field of Product Design. Springer, Berlin Heidelberg, 2009.

[11] M. Marti, Complexity Management - Optimizing Product Architeture of Industrial Products, Springer Fachmedien, Wiesbaden, 2007.

[12] J. Jiao, T. W. Simpson, and Z. Siddique, Product family design and platform-based product development: A state-of-the-art review, Journal of Intelligent Manufacturing, vol. 18, no. 1, pp. 529, 2007.

[13] A. Brun and M. Zorzini, Evaluation of product customization strategies through modularization and postponement, International Journal of Production Economics, vol. 120, no. 1, pp. 205-220, Jul. 2009.

[14] K. Ramdas, Managing product variety: An integrative review and research directions, Production and Operations Management, vol. 12, no. 1, pp. 79-101, 2003.

[15] A. Haug, L. Hvam, and N. H. Mortensen, The impact of product configurators on lead times in engineering-oriented companies, Artificial Intelligence for Engineering Design, Analysis and Manufacturing, vol. 25, no. 02, pp. 197-206, Apr. 2011.

[16] S. Shafiee, K. Kristjansdottir, L. Hvam and C. Forza, How to scope configuration projects and manage the knowledge they require, Journal of Knowledge Management, vol. 22, no. 5, pp. 982 $1014,2018$.

[17] S. Shafiee, L. Hvam, and M. Bonev, Scoping a product configuration project for engineer-to-order companies, International Journal of Industrial Engineering and Management, vol. 5, no. 4, pp. 207 $220,2014$.

[18] L. Hvam, C. Hansen, C. Forza, N. H. Mortensen, and A. Haug, The reduction of product and process complexity based on the quantification of product complexity costs, International Journal of Production Research, vol. 0, no. 0, pp. 1-17, 2019.

[19] A. Oakley, People's way of knowing: gender and methodology," in S. Hood, B. Mayall and S. Oliver (eds.) Critical Issues in Social Research, Open University Press, Buckingham, 1999, pp. 154-177.

[20] M. Rudberg and J. Wikner, Mass customization in terms of the customer order decoupling point, Production Planning and Control, vol. 15, no. 4, pp. 445-458, 2004.

[21] J. Geraldi, H. Maylor and T. Williams, Now, let's make it really complex (complicated): A systematic review of the complexities of projects, International Journal of Operations and Production Management, vol. 31, no. 9, pp. 966-990, 2011.

[22] S. Wilson and A. Perumal, Waging war on complexity costs. McGraw-Hill Professional Publishing, New York, 2009.

[23] R. Koch, The 80/20 Principle: The Secret of Achieving More with Less: Updated 20th anniversary edition of the productivity and business classic. Hachette, London, 2011.

[24] H. Puhl, Komplexitätsmanagement: ein Konzept zur ganzheitlichen Erfassung, Planung und Regelung der Komplexität in Unternehmensprozessen, PhD thesis, Kaiserslautern, 1999.

[25] A. Griffin, Metrics for measuring product development cycle time, The Journal of Product Innovation Management, vol. 10, no. 2, pp. 112-125, 1993.

[26] D. H. Grabenstetter and J. M. Usher, Determining job complexity in an engineer to order environment for due date estimation using a proposed framework, International Journal of Production Research, vol. 51, no. 19, pp. 5728-5740, 2013.

[27] A. Griffin, The Effect of Project and Process Characteristics on Product Development Cycle Time, Journal of Marketing Research, vol. 34, no. 1, p. 24, 1997.

[28] H. A. Bashir and V. Thomson, Metrics for design projects: a review, Design studies, vol. 20, no. 3, pp. 263-277, 1999.

[29] H. a. Bashir and V. Thomson, Models for estimating design effort and time, Design Studies, vol. 22, no. 2, pp. 141-155, 2001.

[30] Y. Kang, The function tree analysis for new product development \& its applications, 2010, http:/trizsummit.ru/file.php/id/f4793/name/thesiscomplete_revised\%200625_007.pdf.

[31] N. Orfi, J. Terpenny and A. Sahin-Sariisik, Harnessing product complexity: Step 1 establishing product complexity dimensions and indicators, Engineering Economist, vol. 56, no. 1, pp. 59-79, 2011.

[32] R. K. Yin, Case Study Research: Design and Methods. Sage publications, Newbury Park, 2003. 